NATIOHAL RUSEAU OE ECOMOMR RESEARCH, IRC.

204 JUMEED SERBA BLVD.

SIAHEDRD, CALIFORIIA SI3B5

\title{
Price Inflation, Portfolio Choice and Nominal Interest Rates
}

\author{
Benjamin M. Friedman \\ Harvard University and NBER
}

Working Paper No.

235

\section{NATIONAL BUREAU OF ECONOMIC RESEARCH, INC. \\ 1737 Cambridge Street \\ Cambridge, Massachusetts 02138}

\section{January 1978 \\ Revised}

This paper has not undergone the review accorded official NBER publications; in particular, it has not been submitted for approval by the Board of Directors. 
PRICE INFLATION, PORTFOLIO CHOICE, AND NOMINAL INTEREST RATES

Benjamin M. Friedman

Harvard University

\section{Abstract}

Among the different kinds of economic behavior which may account for the familiar Fisherian relationship between nominal interest rates and expected price inflation, portfolio behavior is the most plausibly flexible in the short run. Since substitution into real assets is not a practical portfolio alternative for many investors, however, it is not obvious a priori how important lenders' portfolio behavior can be in bringing about the adjustment of interest rates which Fisher's theory associates with expected inflation. Given the importance of this adjustment for questions of both monetary theory and monetary policy, the underlying economic behavior merits explicit investigation.

The empirical results presented in this paper provide evidence that lenders' portfolio behavior does play an important role in the expected-priceinflation/nominal-interest-rate relationship. First, results indicate that five of the six major categories of investors in the U.S. long-term bond market reduce their demands for bonds in response to an increase in expected inflation. Secondly, the results of multi-equation partial-equilibrium experiments indicate that, with all other things unchanged, this response by investors will raise the equilibrium nominal bond yield by about $2 / 38$ in response to a 18 increase in expected inflation. 
Revised

January, 1978

\title{
PRICE INFLATION, PORTFOLIO CHOICE, AND NOMINAL INTEREST RATES
}

\author{
Benjamin M. Friedman* \\ Harvard University
}

The belief that expectations of future price inflation tend to result in higher nominal interest rates -- the proposition which Irving Fisher, in a perhaps more optimistic era, labeled "appreciation and interest" ${ }^{1}$-- is now commonplace among both economists and financial market participants. The rise of nominal interest rates in the United States to record high levels in 1974, just when the U.S. economy was undergoing its first experience of peacetime double-digit inflation, dramatically demonstrated this relationship at even the most unsophisticated eyeball level. Many economists have also undertaken statistical investigations of this relationship, using a variety of devices to obviate the analytical difficulties due to the unobservability of the relevant expectations. $^{2}$ with 1 ts imediate implications for real yields, the Fisher relationship is central to the classic questions confronting monetary theory and policy.

Many important aspects of the expected-price-inflation/nominal-interestrate relationship remain undetermined, however. In the comparative statics context of a long-run steady-state equilibrium, do nominal yields adjust on a one-for-one basis with fully anticipated inflation, thereby leaving real yields unaffected? In the dynamic context of a transition from one such equilibrium to another, are the lags associated with expectation formation (which Fisher emphasized) the only reason why nominal yields may adjust slowly toward their new steady-state values? Alternatively, to what extent are other lags involved, arising either from limited speeds of portfolio adjustment out of 
equilibrium or from gradual changes in saving and investment behavior? At the most fundamental level, what is the exact nature of the process by which economic behavior causes nominal interest rates to respond to price expectations in the specified way? Fisher himself was curiously sketchy in his "interpretation" of the relationship, ${ }^{3}$ and most subsequent writers on the subject have followed his lead in seeking more to document and quantify the relationship than to investigate in any precise way the underlying economic behavior which causes it.

The object of this paper is to explore in some detail one of the possible sources of the Fisher relationship -- in particular, the portfolio behavior of lenders. The starting point for this analysis is the simple truism that, for expectations of price inflation to affect interest rates, they must affect the behavior of lenders or borrowers (or both). Responses to such expectations on the part of lenders and borrowers could logically involve not only their portfolio behavior (the composition of their assets held and liabilities issued) but also their saving and investment behavior (the amounts of their assets held and liabillties issued). This paper's specific focus is on the role of lenders' portfolio behavior in the relationship between price expectations and nominal interest rates, and the paper investigates this role using behavioral equations directly explaining lenders' willingness to enter into long-term fixed-income loan contracts. 4 To anticipate, the conclusion of the paper's partial-equilibrium analysis is that lenders' portfolio behavior is an important component of the economic process generating the Fisher relationship. Results based on U.S. data indicate that, with all other aspects of economic behavior held unchanged, lenders' portfollo behavior would cause the equilibrium level of nominal bond yields to rise by 0.658 for each 18 of expected price inflation. 
Section I discusses several different hypotheses about economic behavior which would logically support Fisher's relationship between price expectations and nominal interest rates, and explains the particularly interesting features of those which turn on portfolio behavior. Section II develops the key behavioral equations describing lenders' demand for long-term fixed-interest loans, and Section III presents estimation results for these equations based on U.S. data for six major categories of lenders. Section IV presents partialequilibrium simulation results showing the implications of lenders' portfolio behavior, as represented by these estimated equations, for the relationship between expected price inflation and nominal yields. Section v briefly summarizes the paper's conclusions. 
I. Portfolio Behavior and the Fisher Relationship

Since there is widespread agreement not only on the importance of expected real yields in influencing economic activity but also on the ability of monetary policy to cause price inflation, the equilibrium extent and the dynamic speed of the adjustment of nominal interest rates to expected inflation are crucial determinants of the ability of monetary policy to influence economic activity in the long and short runs, respectively. The great concern which economists have shown with the expected-price-inflation/nominal-interest-rate relationship is therefore hardly surprising.

Fisher assumed that, in long-run steady-state equilibrium, nominal yields adjust on a one-for-one basis with expected price inflation, thereby leaving real yields (and hence real economic activity) invariant to fully anticipated inflation. By contrast, Mundell [50] and Tobin [69] have argued -- in static and dynamic models, respectively -- that, given the fixed nominal yield (conventionally zero) on money balances, the inevitable reduction in the real yield on money which is consequent upon price inflation will cause a corresponding reduction in real yields on other assets. According to the Mundell-Tobin view, therefore, nominal yields will adjust less than one-for-one with expected inflation, and real economic activity will itself depend on the rate of inflation. More recently, Darby [9] and Feldstein [13] have conversely argued that the distortion introduced by price inflation under non-indexed taxation will cause the adjustment of nominal yields to be greater than one-for-one. The precise equilibrium nature of the Fisher relationship -- and with it the equilibrium effectiveness of monetary policy -- is therefore an open question.

Even if nominal yields do adjust fully for expected inflation in long-run steady-state equilibrium, there remains the question of the short-run effectiveness of monetary policy if the adjustment is not instantaneous. Fisher relied 
largely on lags in (autoregressive) expectation formation to explain the observed lag of nominal interest rate movements behind actual price movements, but -- in sharp contrast to the typical modern rendering of his views -- he did not assume either that real yields are constant (or constant to a white noise), or that they remain invariant to price inflation in the short run. 5 In addition, at least in his early work Fisher argued that, in the short run, asymmetrical behavior between lenders and borrowers further rendered real yields systematically dependent on the rate of price inflation. ${ }^{6}$ The well documented lags associated with a number of relevant aspects of economic behavior, including construction and delivery times for physical investment and the transactions costs of portfolio adjustment, provide yet additional potential sources of a lagged relationship and further suggest that even fully anticipated price inflation may influence real yields -- and, consequently, that monetary policy may influence real economic activity -- in the short run.

Many economists have investigated these important questions by working directly with the relationship between nominal interest rates and price expectations. $^{7}$ It is clear, however, that this relationship is at best (if price expectations are meaningfully exogenous) a reduced-form relationship which presumably follows from -- but does not explicitly reveal -- some underlying behavioral structure. 8 In the more general case without the exogeneity assumption for price expectations, the Fisher relationship is a connection between two endogenous variables within a structural model.

In attempting to shed light on the questions posed above about the equilibrium extent and dynamic speed of Fisher's adjustment of nominal interest rates to expected price inflation, therefore, it is useful first to identify the specific kinds of individual optimizing behavior which may plausibly 
produce the observed adjustment. Nominal interest rates are relative prices set on loan agreements struck between lenders and borrowers. Since these nominal yields (or, conversely, prices of loan agreements) are proximately determined in a market in which loans are extended and received, it is a truism that any factor hypothesized to influence such yields (prices) must do so by influencing some lender's demand for loans, or some borrower's supply of loans, or both. 9 For expectations of future price inflation to increase nominal interest rates, therefore, the behavioral process by which they do so must involve creating a net excess supply of loans by reducing lenders' willingness to lend and/or increasing borrowers' willingness to borrow at a given nominal yield.

In what way may price expectations have this effect? Two broad groups of hypotheses, both based on the appealing assumption that it is the expected utility of real wealth which matters for economic behavior, are able to provide some explanation.

First, saving and investment behavior may plausibly be responsive to anticipated real yields. From the standpoint of lenders, the simplest example is a household which decides to consume more and save less, at a given nominal interest rate, when expectations of price inflation shift the perceived intertemporal consumption possibility frontier in favor of current consumption. Hence the demand for total portfolio wealth in general, and for loans in particular, is smaller. From the standpoint of borrowers, the analogous example is a f1rm which decides to do more loan-financed investment, at a given nominal interest rate, when expectations of price inflation increase the expected revenue stream from sales of future output. Hence the supply of loans is greater. In either case the resulting net excess supply of loans means that the nominal interest rate must rise to clear the loan market. 
Secondly, portfolio behavior may also be plausibly related to anticipated real yields, so that price expectations may affect choices with respect to the composition of assets held and liabilities outstanding, wholly apart from the respective totals. ${ }^{10}$ In a world of risk neutrality and zero transactions costs, for example, a straightforward extension of the principle of Hicks [36] and Lutz [44] is that lenders (investors) would presumably fully arbitrage any difference in expected real holding-period yields among all nominal-interest loans and all storable commodities. In practice, however, the available opportunities for such portfolio substitutions involving consumption comodities are usually extremely limited. Furthermore, while many investors can substitute equities for fixed-return assets (money or loans) in their portfolios, recent empirical and theoretical work has shown that equities are hardly an effective "inflation hedge" in any short or intermediate run and has even cast doubt on the long-run relationship between equity returns and price inflation. ${ }^{11}$ Hence simple propositions, framed as if investors could actively arbitrage between nominal interest bearing assets and the consumer-price-index basket of goods, are inadequate for understanding the workings of the Fisher relation.

Nevertheless, even absolute barriers to portfolio substitution between commodities and nominally denominated assets need not preclude investors' portfolio behavior from having a key influence on the dynamics which connect expected price inflation and nominal interest rates. As long as investors have at least the choice between money (or, equivalently, short-term interest bearing assets) and loans (of long duration), and as long as price inflation will eventually affect some real variable, then investors' portfolio behavior can still be the immediate vehicle by which expected price inflation affects nominal yields. For example, investors expecting higher goods prices in the 
future will probably expect that the associated greater nominal volume of transactions will increase the demand for money and therefore drive up nominal interest rates (drive down loan prices) in the future. To avoid the resulting capital losses on holding loans, such investors will act currently to substitute money for loans in their portfolios, thereby causing a rise in nominal yields (a fall in loan prices) to occur even while the anticipated higher goods prices remain only an expectation rather than a reality. ${ }^{12}$ similarly, investors expecting price inflation may anticipate higher nominal interest rates to follow, either because of the monetary authority's policy response to the inflation or because of eventual induced changes in saving and investment behavior. Once again, portfolio substitutions of money for loans, intended to avoid capital losses, will cause an immediate rise in nominal yields. ${ }^{13}$

Hence even under the assumption of severely limited substitution possibilities, which preclude investors' portfolio behavior from being the ultimate source of the adjustment of nominal interest rates to price expectations, this behavior may still substantially influence the dynamics of the adjustment process. Especially since the changes in saving and investment behavior which may ultimately underlie the Fisher relationship presumably involve substantial time lags, the role of portfolio behavior is a crucial determinant of whether expected real yields reach their equilibrium (perhaps unaltered) levels quickly or with a (perhaps exploitable) lag.

The specific object of attention in this paper is the role of lenders' portfolio behavior in producing the adjustment of nominal interest rates to expected price inflation. Sections II and III below develop and estimate equations representing, with special attention to the influence of price expectations, the maximizing behavior of lenders in the market which many 
previous researchers have also chosen to reflect most clearly the Fisher relationship -- in particular, the market for long-term fixed-interest loans (bonds). Section IV then uses a partial-equilibrium methodology to examine the implications of lenders' portfolio behavior, as represented by these equations, for the relationship between nominal interest rates and expected price inflation. 
II. A Model of Lenders' Demand for Loans

It is well known that, for risk averse investors maximizing the expected utility of either terminal wealth or portfolio rate of return, the optimal portfolio allocation depends not only on the means but also on the higher moments of the distributions describing the expected holding-period rates of return on each individual asset available for portfolio investment. Under the simplifying assumption of joint normally (or lognormally) distributed rates of return, therefore, optimal portfolio allocation depends on the means, variances and covariances of the individual expected asset yields. ${ }^{14}$ In the familiar linear homogeneous form, the resulting model of desired portfolio allocation is the expression ${ }^{15}$

$$
\frac{A_{i t}^{*}}{w_{t}}=\sum_{k}^{N} \beta_{i k} r_{k t}^{e}+\sum_{k}^{N} \gamma_{i k} v_{k t}+\sum_{k}^{N} \sum_{j \neq k}^{N} \delta_{i k j} c_{k j t}+\pi_{i}, \quad i=1, \ldots, N
$$

where

$$
\begin{aligned}
& A_{i t^{\prime}}^{*} i=1, \ldots, N=\text { the investor's desired holding of the } i-t h \\
& \text { asset at time period } \left.t \underset{i}{\left(\sum A_{i t}^{*}\right.}=w_{t}\right) \\
& w_{t} \quad=\text { the investor's total portfolio size (wealth) } \\
& \text { at time period } t \\
& r_{k t^{\prime}}^{e} k=1, \ldots, N=\text { the expected value of the holding-period } \\
& \text { yield on the k-th asset at time period } t \\
& v_{k t}, k=1, \ldots, N=\text { the variance associated with } r_{k t}^{e} \\
& c_{k j t}, k, j=1, \ldots, N=\text { the covariance associated with } r_{k t}^{e} \text { and } r_{j t}^{e}
\end{aligned}
$$

and the $\beta_{i k}, \gamma_{i k}, \delta_{i k j}$ and $\pi_{i}$ are fixed coefficients which satisfy $\sum_{i k} \beta_{i k}=$ $\sum_{i} \gamma_{i k}=0$ for all k, $\sum_{i} \delta_{i k j}=0$ for all $k$ and $j$, and $\sum_{i} \pi_{i}=1$. On the assumption of universal substitutability, the $\beta_{i k}$ and $\gamma_{i k}$ also satisfy $\beta_{i k}>0>\gamma_{i k}$ ' 
$i=k$, and $\beta_{i k}<0<\gamma_{i k^{\prime}} i \neq k$. The expression for the investor's desired holding of loans $\left(L_{t}^{*}\right)$, for example is (without the covariances)

$$
\frac{L_{t}^{*}}{W_{t}}=\beta_{L L} r_{L t}^{e}+\sum_{k \neq L}^{N} \beta_{L k} r_{k t}^{e}+\gamma_{L L} v_{L t}+\sum_{k \neq L}^{N} \gamma_{L k} v_{k t}+\pi_{L}
$$

where the coefficients of the holding-period yield expectations and variances satisfy $\beta_{L L}>0>\gamma_{L L}$ and $\beta_{L k}<0<\gamma_{I k^{\prime}} k \neq L$.

What is the role of expected price inflation within a portfolio choice framework like (1) and (2)?. If real assets constitute a plausible asset for portfolio investment, then the effect of price expectations here is striaghtforward. The increase in goods prices is then simply the holding-period return on investment in such real assets, and the associated expectation $r_{p}^{e}$ is an argument of $(2)$. The associated coefficient $\beta_{L P}$ is negative so that, for all other things equal, greater expectations of price inflation reduce lenders' demand for loans. Following the discussion of section I, however, purchasing the consumer-price-index basket of goods is not in fact a practical portfolio alternative.

For expected price inflation to influence lenders' portfolio behavior under limited portfolio substitution possibilities, therefore, inflation expectations must differentially affect the expected holding-period returns (or variances or covariances) on those assets which do constitute plausible portfolio choices. For example, expected inflation may increase the expected return to equities relative to expected returns on money and loans (of all maturities) which have fixed nominal yields. Alternatively, again in the term-structure context, investors may expect the future price inflation to bring higher future nominal interest rates, thereby increasing the expected long-holding-period return on a series of short-term loans relative to that on a long-term loan -- or, 
equivalently, to bring lower future loan prices, thereby reducing the expected short-holding-period return on a long-term loan relative to that on a single short-term loan. ${ }^{16}$ Even for an investor who cannot practically invest in real assets, therefore, the demand-for-loans expression (2) may depend on expectations of price inflation via their influence on the expected asset returns $r_{k}^{e}$. Moreover, if the investor associates uncertainty of asset returns with uncertainty of price inflation, then the variance (and relevant covariances) of price expectations will also be a determinant of the demand for loans.

The general portfolio allocation model (1), as well as the specific loan demand expression (2), describes the determination of variables which are unobservable in the presence of transactions costs. Consequently, it is necessary to apply some model of portfolio adjustment to translate the implications of such expression into an operational model of behavior. The "optimal marginal adjustment" model developed in Friedman [23] is useful for this purpose, in that it generalizes the familiar stock adjustment model so as to relate the investor's short-run portfolio adjustments not only to the discrepancies $\left(A_{i t}^{*}-A_{i, t-1}\right), i=1, \ldots, N$, between the desired asset holdings from selection model (1) and the corresponding previous-period holdings but also to the current investable cash flow. The primary rationale for distinguishing the cash flow in this context is that current cash flows are typically more easily (costlessly) allocated than are existing asset holdings. Since transactions costs constitute, in the first instance, the underlying motivation for using a model which admits discrepancies between actual and desired portfolio holdings, ${ }^{17}$ it is worth while to model the implications of transactions costs with some care. The optimal marginal adjustment model incorporates in a tractable form the differential transactions costs between the investor's allocation of a new cash flow and 
re-allocation of existing asset holdings by positing the allocation of the current cash flow according to whatever proportions portfolio selection model (1) indicates are desired for the total portfolio.

Given an investor's beginning-of-period wealth and current-period cash flow, the optimal marginal adjustment model is

$$
\Delta A_{i t}=\sum_{k}^{N} \theta_{i k}\left(\alpha_{k t}^{\star} W_{t-1}-A_{k, t-1}\right)+\alpha_{i t}^{*} \Delta W_{t^{\prime}} \quad i=1, \ldots, N
$$

where the desired equilibrium proportions

$$
\alpha_{i t}^{*} \equiv \frac{A_{i t}^{*}}{w_{t}}, \quad i=1, \ldots, N \quad \underset{i}{\left(\sum \alpha_{i}^{*}=1\right)}
$$

follow from (1), and the $\theta_{i k}$ are fixed coefficients of adjustment satisfying $\sum \theta_{i k}=\bar{\theta}$ for all $k$, with $\bar{\theta}$ arbitrary. Heuristically, the first term on the right-hand side of (3) represents the re-allocation, according to a standard multivariate stock-adjustment model, of the investor's existing asset holdings $A_{i, t-1}, i=1, \ldots, N$ (which sum to the beginning-of-period wealth $w_{t-1}$ ), while the second term represents the allocation of the investor's current-period cash flow $\Delta w_{t}$ according to the desired equilibrium proportions $\alpha_{i t^{\prime}}^{*} i=1, \ldots N$. The key advantage of the optimal marginal adjustment model in the context of this paper is that it captures the greater sensitivity to expected holding-period yields (and inflation) of the allocation of the flow $\Delta w_{t}$ in comparison with the reallocation of the stock $w_{t-1}$.

Expanding portfolio adjustment model (3), using the desired loan demand expression (2) as a specific component of portfolio selection model (1), yields an operational equation for investors' short-run demand for loans:

$$
\begin{aligned}
\Delta \mathrm{L}_{t}= & \pi_{L} \cdot \Delta \mathrm{W}_{t}+\underset{k}{\left[\Sigma\left(\pi_{k} \cdot \theta_{L k}\right)\right] \cdot W_{t-1}} \\
& +\beta_{L L} \cdot r_{L t}^{e} \cdot \Delta W_{t}+\underset{k}{\left[\Sigma\left(\beta_{k L} \cdot \theta_{L k}\right)\right] \cdot r_{L t}^{e} \cdot W_{t-1}}
\end{aligned}
$$




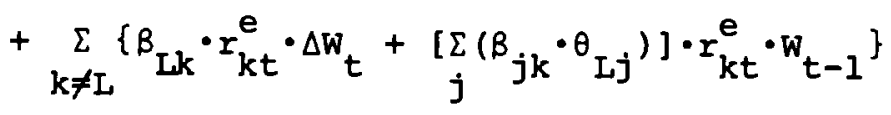

$$
\begin{aligned}
& \left.\left.+\gamma_{L L} \cdot v_{L t} \cdot \Delta W_{t}+\underset{k}{\left[\sum _ { k L } \left(\gamma_{L k}\right.\right.} \cdot \theta_{L t}\right)\right] \cdot v_{L t} \cdot W_{t-1} \\
& \left.\left.+\sum_{k \neq L}\left\{\gamma_{L k} \cdot v_{k t} \cdot \Delta w_{t}+\underset{j}{\left[\sum \left(\gamma_{j k}\right.\right.} \cdot \theta_{L j}\right)\right] \cdot v_{k t} \cdot w_{t-1}\right\} \\
& -\theta_{L L} \cdot L_{t-1}-\sum_{k \neq L} \theta_{L k} \cdot A_{k, t-1} .
\end{aligned}
$$

Here it is useful to distinguish the particular right-hand-side terms which do and do not have coefficients of known sign a priori. Each expected holdingperiod yield $r_{k}^{e}$ and variance $v_{k}, k=1, \ldots, N$ (including the own-yield $r_{L}^{e}$ and own-variance $v_{L}$ ) enters (5) twice, in nonlinear form both times. In each case the product of $r_{k}^{e}$ or $v_{k}$ and the flow $\Delta w_{t}$ bears a coefficient which consists of a single parameter of known sign from (1). Similarly, the lagged own-stock $L_{t-1}$ enters (5) with coefficient $-\theta_{L L}<0$ from the stock-adjustment component of (3). All other right-hand-side terms in (5) -- including the linear terms $\Delta W_{t}, W_{t-1}$ and $A_{k, t-1}, k \neq L$, as well as all nonlinear terms consisting of products of $r_{k}^{e}$ or $v_{k}$ with $w_{t-1}$-- bear coefficients which are of unknown sign a priori. ${ }^{18}$ Since the models of desired equilibrium portfolio behavior (1) and short-run portfolio adjustment (3) underlying loan demand equation (5) deal with the investor's demands for all assets (and supplies of all liabilities), (5) is implicitly an element of a set of demand equations which satisfy the various "adding-up" constraints specified above. By contrast, the more limited focus of this paper is on the nature of investors' demands for loans -- more specifically, long-term loans -- and on the partial-equilibrium implications of these demands for the relationship between expected price inflation and nominal interest rates. As Ladenson [37] and Smith [66] have shown, it is not 
necessary to use constrained estimation techniques to guarantee that the parameter estimates of the full set of demand equations satisfy the "adding-up" constraints, so that there is no inconsistency involved in estimating only one demand equation rather than the entire set. In principle, however, even for the limited objective at hand, a complete model including all assets (and liabilities too) would be preferable. In particular, a complete model would not only facilitate a general-equilibrium analysis but also permit the researcher to adopt the philosophy as well as the mechanics of Brainard and Tobin [6] by examining the implications for other asset demand equations of the presence of a given variable in any one asset demand equation. The construction of such a complete model, however, lies well beyond the scope of this paper.

Section III presents the results of estimating loan demand equation (5) applied to the demand for long-term fixed-interest loans by six separate categories of U.S. lenders. 


\section{Estimation Results}

Preliminary Issues. It is useful at the outset to comment briefly on several aspects of the specification and estimation of the loan demand equations presented below.

Disaggregation: The equations presented below represent the demand for long-term loans to private borrowers (that is, long-term corporate bonds) by six categories of U.S. lenders which together held approximately 938 of all such loans outstanding in the United States as of yearend 1976: life insurance companies (34.4\%), other insurance companies (4.0\%), private pension funds (11.08), state and local government retirement funds (19.3\%), mutual savings banks (5.7\%), and households ${ }^{19}(18.48)$. This disaggregation is useful because such diverse lenders --which face different legislative and regulatory constraints, and play different roles in the markets' highly complex intermediation structure -- are unlikely to exhibit identical portfolio responses to expected price inflation. For example, although life insurance companies must earn real dividends, since their liabilities are almost exclusively in nominal form it is not obvious that their asset demands are highly sensitive to expected real yields in the short run. In addition, life insurance companies in most states can invest only a small fraction of their portfolios in equities. By contrast, many pension funds face liabilities which are either explicitly or implicitly indexed to consumer goods prices, and private pension funds in particular have substantially more latitude in allocating their portfolios.

Data: The primary data source for the stock and flow quantities used to estimate these equations is the Federal Reserve System's flow-of-funds accounts [1, and subsequent issues]. ${ }^{20}$ These data are seasonally adjusted and are denominated in millions of dollars. The sample period consists of 56 quarterly observations beginning in 1960:I and ending in 1973:IV. 
The particular nominal interest rate $r_{L}$ used in these equations is the observed new-issue yield on long-term bonds issued by utility companies rated Aa by Moody's Investors Service, Inc. Aa-rated utility bonds provide the greatest continuity, in terms of the frequency of new issues; they are also most representative of new-issue activity in the U.S. market. Previous studies of long-term nominal interest rate determination using the reduced-form term-structure approach have relied on indices of yields either on new issues or seasoned issues, but the new-issue yield is likely to be superior for several reasons. First, trading in the corporate bond market involves either new issues or recent issues to a far greater extent than seasoned issues, and quoted price movements among seasoned issues are often just a reflection of what is happening in the new-issue market. Secondly, because of thin trading markets, problems of measurement are considerably smaller for new issues than for seasoned issues. Thirdly, differences in coupon rates between current new issues and the issues used in constructing seasoned yield indices introduce a form of bias into the seasoned yield index itself.

Instrumental variables estimation: Since the own-yield on long-term loans is jointly determined by lenders' demands for loans and borrowers' supplies of loans, it is necessary to allow for this simultaneity in deriving consistent estimates of the loan demand equations. The relevant set of instruments used here for deriving consistent estimators includes not only the exogenous variables in the six respective disaggregated demand equations but also the exogenous variables in the two disaggregated loan supply equations developed in Friedman [22]. As is typically the case in multi-equation models, it is impossible to apply the two-stage least-squares method directly because there are too many exogenous variables to permit ordinary least-squares estimation of the system's reduced form as this method requires. The procedure used here 
follows Brundy and Jorgenson [5] in using as instrumental variables not only the leading principal components of the full-system set of exogenous variables but also, on an equation-by-equation basis, the single-equation sets of exogenous variables themselves.

Intercepts: Equation (5) has no intercept term, but it is probably accurate to consider the portfolio behavior model developed in section II as a linear approximation to a more complex behavioral pattern, and an intercept may follow from linearization. The procedure used here includes or excludes an intercept in each loan demand equation according to the t-statistic.

Expectations proxies: Since lenders' expectations are unobservable, both for price inflation and for nominal holding-period returns on assets subject to capital gains or losses, it is necessary to use some indirect representation in their place. Nevertheless, no sharp consensus exists on the best form of expectations proxy to use for such purposes. The approach adopted here, therefore, is to estimate each of the six loan demand equations twice -- once using an autoregressive and once using a rational representation of lenders' expectations.

\section{Results Based on Autoregressive Expectations. A familiar representation} of expectations, used by many of the researchers who have explored the relationship between expected price inflation and nominal interest rates, is that market participants form their expectations of relevant variables on the basis of previously observed values of these variables. Following Nerlove [53], a general autoregressive expectation mechanism of the form

$$
\left.E_{t} \tilde{x}_{t+1}\right)=\sum_{i=0} \omega_{i} x_{t-i}
$$

where $E_{t}(\cdot)$ is the expectation held at time $t$, the $\omega_{i}$ are lag weights and the 
tilde indicates that variable $\tilde{x}_{t+1}$ is unknown as of time $t$, is consistent with the optimal linear prediction of a time series from its own past history. Several familiar simple expectations mechanisms, such as the "naive" model that next period will be like last period, or Cagan's [6] adaptive expectation, are special cases of autoregressive expectations. More generally, Modigliani and Shiller [48] have usefully illustrated, also in the context of interest rate and price expectations, that autoregressive expectations are consistent with a combination of extrapolative and regressive components. To emphasize the contrast to the more restrictive adaptive schemes, some writers have referred to such general autoregressive expectations mechanisms as "partly rational" or "weak-form rational." 21

Table 1 shows the results of estimating loan demand equation (5), for each of the six categories of lenders indicated above, using autoregressive representations of the relevant expectations. The variable symbols are consistent for all six equations, with letter superscripts indicating distinctions among corresponding variables for the respective categories of lenders. Asterisk superscripts indicate terms for which an equation is estimated using fitted values of the variable from the first stage of the instrumental variables procedure. 22 The numbers in parentheses are ratios of estimated coefficients to the corresponding standard errors. ${ }^{23}$

Following the autoregressive model, these equations use distributed lags on past'percentage changes of the consumer price index, past percentage changes in the one-period loan yield, and past percentage changes in equity prices to represent the influence of these past observations on lenders' expected holding-period yields. Similarly, these equations use computed moving-average variances to represent the second moments of the distributions describing 


\section{Table 1}

IOAN DEMAND EQUATIONS BASED ON AUTOREGRESSIVE EXPECTATIONS

\section{Life Insurance Companies}

$$
\begin{aligned}
& \Delta \mathrm{L}_{t}^{\mathrm{L}}=\underset{(5.9)}{0.1716} \mathrm{w}_{t-1}^{\mathrm{L}}+\underset{(2.9)}{0.2193}\left(r_{L t} \cdot \Delta \mathrm{w}_{t}^{\mathrm{L}}\right)^{*} \underset{(-3.5)}{-0.03203} \sum_{i} \phi_{i} \Delta r_{S, t-i} \cdot \Delta \mathrm{W}_{t}^{\mathrm{L}}
\end{aligned}
$$

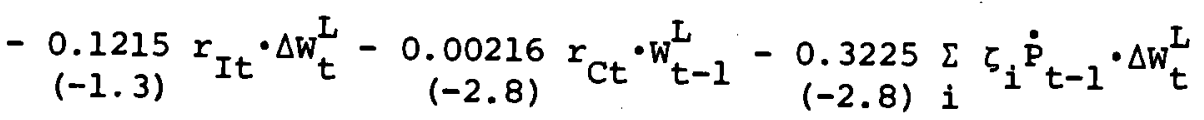

$$
\begin{aligned}
& +\underset{(2.9)}{0.00457 \sum_{i} \zeta_{i} \dot{P}_{t-i} \cdot w_{t-1}^{L}}-\underset{(-1.7)}{2.241} v_{L t} \cdot \Delta w_{t}^{L}+\underset{(1.4)}{0.02475} v_{L t} \cdot w_{t-1}^{L} \\
& +\underset{(1.7)}{1.398} \mathrm{v}_{\mathrm{Bt}} \cdot \Delta \mathrm{W}_{\mathrm{t}}^{\mathrm{L}}-\underset{(-5.6)}{0.3551} \mathrm{~L}_{\mathrm{t}-1}^{\mathrm{L}}-\underset{(-2.6)}{0.1405 \mathrm{I}_{\mathrm{t}-1}^{\mathrm{L}}} \\
& \mathrm{SE}=154 \\
& \mathrm{DW}=1.35
\end{aligned}
$$

\section{Other Insurance Companies}

$$
\begin{aligned}
& \Delta \mathrm{L}_{t}^{\mathrm{O}}=\underset{(2.1)}{524.1}+\underset{(2.8)}{0.2570} \mathrm{w}_{\mathrm{t}-1}^{\mathrm{O}}+\underset{(6.2)}{0.0501}\left(\mathrm{r}_{\mathrm{Lt}} \cdot \Delta \mathrm{w}_{\mathrm{t}}^{\mathrm{O}}\right)^{*}
\end{aligned}
$$

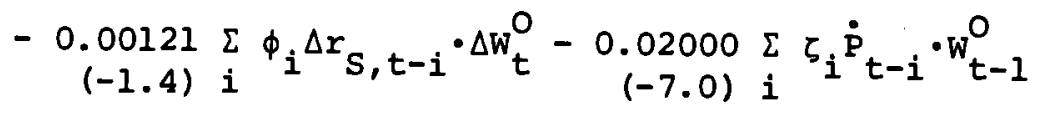

$$
\begin{aligned}
& +\underset{(1.3)}{0.000109} v_{E} \cdot \Delta w_{t}^{0}-\underset{(-4.7)}{0.00000846} v_{E} \cdot w_{t-1}^{0}
\end{aligned}
$$

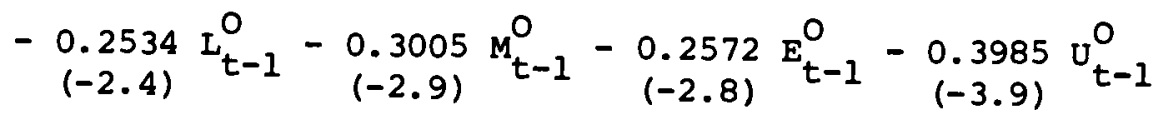

$$
\begin{aligned}
& \bar{R}^{2}=0.96 \\
& S E=42 \\
& D W=1.99
\end{aligned}
$$

\section{Private Pension Funds}

$$
\begin{aligned}
& \Delta L_{t}^{P}=\underset{(2.1)}{0.2892} \mathrm{w}_{t-1}^{\mathrm{P}}+\underset{(3.1)}{0.09953}\left(r_{L t} \cdot \Delta \mathrm{W}_{t}^{\mathrm{P}}\right)^{*}-\underset{(-2.1)}{0.00445} \sum_{i} \phi_{i} \Delta r_{\mathrm{S}, t-i} \cdot \Delta \mathrm{w}_{t}^{\mathrm{P}} \\
& -\underset{(-1.8)}{0.09811} \sum_{i} \zeta_{i} \dot{P}_{t-i} \cdot \Delta W_{t}^{P}-\underset{(-2.1)}{0.000428} \sum_{i} \psi_{i} \dot{Q}_{t-i} \cdot w_{t-1}^{P} \\
& +\underset{(3.0)}{1.323} \mathrm{v}_{E^{\prime} t} \cdot \Delta \mathrm{W}_{t}^{\mathrm{P}}-\underset{(-3.2)}{0.02630} \mathrm{v}_{E^{\prime} t} \cdot \mathrm{W}_{t-1}^{\mathrm{P}}-\underset{(-2.5)}{0.4633} \mathrm{~L}_{t-1}^{\mathrm{P}} \\
& -\underset{(-2.0)}{0.2925} \mathrm{E}_{t-1}^{\mathrm{P}}+\underset{(3.7)}{0.3714} \mathrm{U}_{t-1}^{\mathrm{P}}
\end{aligned}
$$

$\bar{R}^{2}=0.63$ 


\section{Table 1 (Continued)}

State-Local Retirement Funds

$$
\begin{aligned}
& \Delta L_{t}^{S}=\underset{(-2.6)}{-1834}+\underset{(3.4)}{0.2729} \mathrm{w}_{t-1}^{S}+\underset{(2.0)}{0.07650}\left(r_{L t} \cdot \Delta \mathrm{W}_{t}^{S}\right)^{*} \\
& -\underset{(-2.8)}{0.01273 \sum} \sum_{i} \phi_{i} \Delta r_{S, t-i} \cdot \Delta w_{t}^{S}-\underset{(-1.4)}{0.04255} r_{T t} \cdot \Delta w_{t}^{S}
\end{aligned}
$$

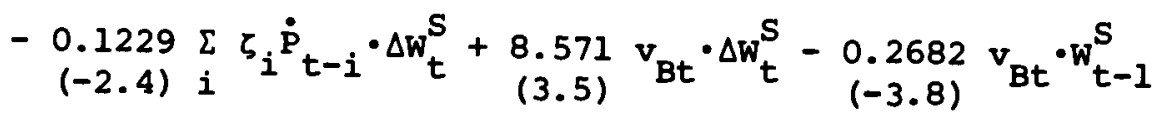

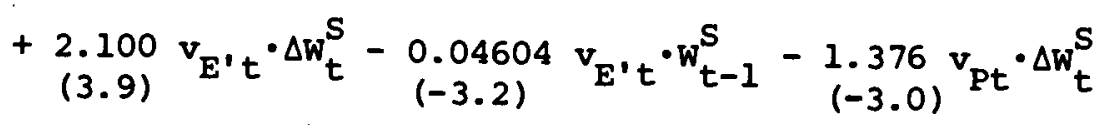

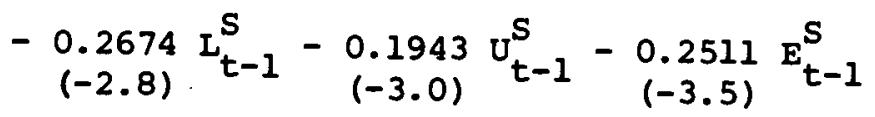

$$
\begin{aligned}
& \overline{\mathbf{R}}^{2}=0.94 \\
& \mathrm{SE}=95 \\
& D W=1.74
\end{aligned}
$$

Mutual Savings Banks

$$
\begin{aligned}
& \Delta L_{t}^{M}=\underset{(6.9)}{4906}+\underset{(6.0)}{0.3767}\left(r_{L t} \cdot \Delta w_{t}^{M}\right)^{*}-\underset{(-4.1)}{0.02573} \sum_{i} \phi_{i} \Delta r_{S, t-i} \cdot \Delta w_{t}^{M} \\
& -\underset{(-4.4)}{0.4265} r_{M t} \cdot \Delta w_{t}^{M}-\underset{(-1.5)}{0.07869 \sum_{i} \zeta_{i} \dot{P}_{t-i}} \cdot \Delta w_{t}^{M} \\
& +\underset{(2.3)}{0.4147} v_{E^{\prime} t} \cdot \Delta W_{t}^{M}-\underset{(-3.7)}{0.01412} v_{E^{\prime} t} \cdot W_{t-1}^{M}-\underset{(-7.0)}{0.2722} L_{t-1}^{M}
\end{aligned}
$$

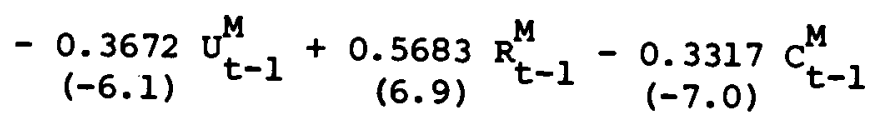

$$
\begin{aligned}
& \overline{\mathrm{R}}^{2}=0.94 \\
& S E=97 \\
& \mathrm{DW}=2.52
\end{aligned}
$$

Households

$$
\begin{aligned}
& \Delta L_{t}^{H}=\underset{(4.2)}{9995}+\underset{(5.1)}{0.06960}\left(r_{L t} \cdot \Delta W_{t}^{H}\right)^{\star}-\underset{(-2.2)}{0.00531} \sum_{i} \phi_{i} \Delta r_{S, t-1} \cdot \Delta w_{t}^{H} \\
& -\underset{(-4.0)}{0.09108} r_{E t} \cdot \Delta w_{t}^{H}+\underset{(4.4)}{0.00142} r_{E t} \cdot w_{t-1}^{H} \\
& -\underset{(-2.3)}{0.03282} \sum_{i} \zeta_{i} \dot{\mathrm{P}}_{t-i} \cdot \Delta w_{t}^{\mathrm{H}}+\underset{(4.1)}{0.00495} \sum_{i} \zeta_{i} \dot{\mathrm{P}}_{t-i} \cdot w_{t-1}^{\mathrm{H}}
\end{aligned}
$$




$$
\bar{R}^{2}=0.86 \quad \begin{gathered}
-0.00337 \\
(-2.2)
\end{gathered} v_{P t} \cdot \Delta W_{t}^{H}-\underset{(-4.0)}{0.2843} I_{t-1}^{H}-\underset{(-4.2)}{0.1533} U_{t-1}^{H}-\underset{(-4.2)}{0.00482} E_{t-1}^{H}
$$

\section{Summary of Variable Symbols}

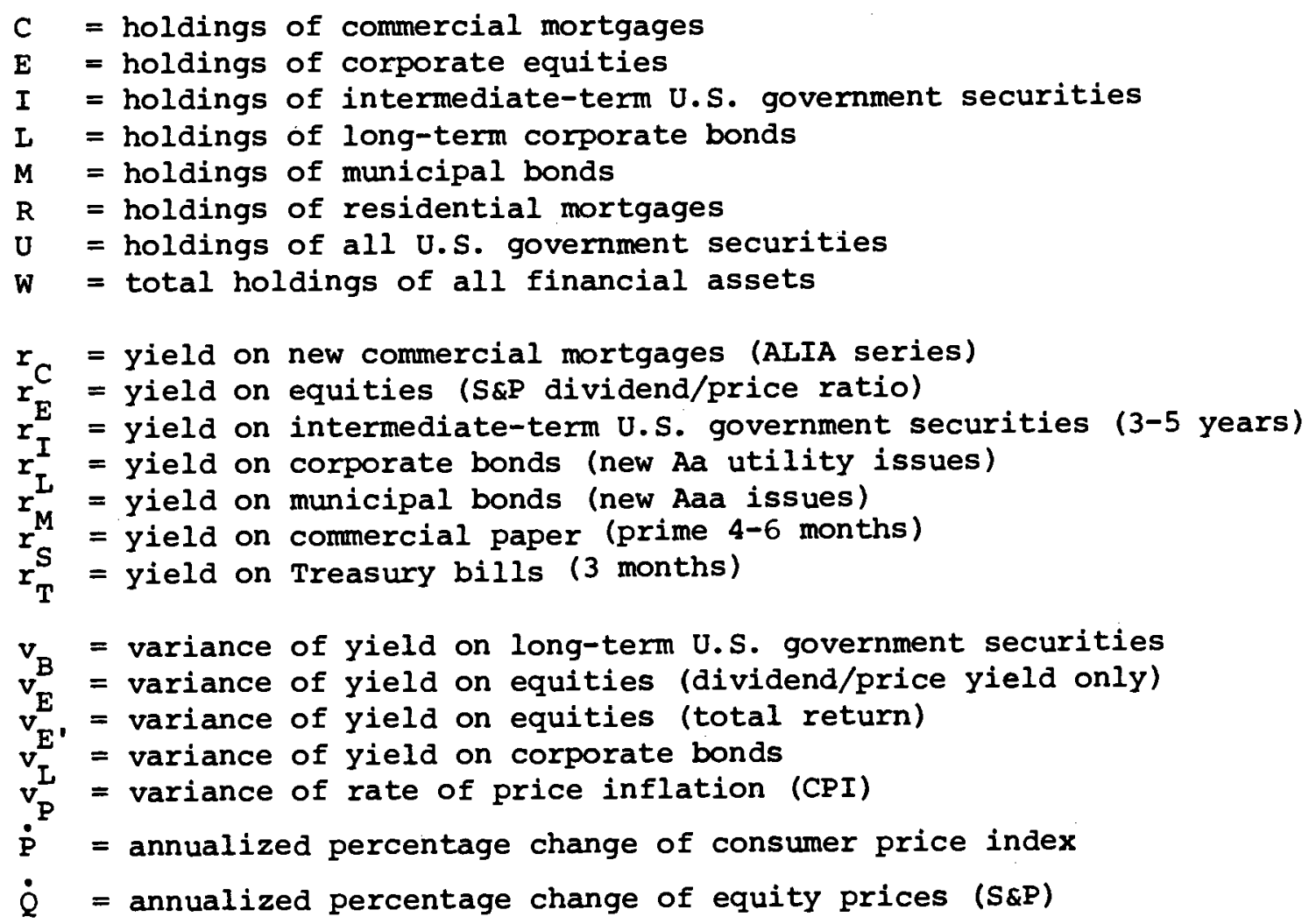

Notes: Numbers in parentheses are ratios of estimated values to standard errors. SE in millions of dollars. 
lenders' expectations. The distributed lags on consumer prices and one-period loan yields are estimated, within the estimation of the loan demand equations, with lag weights constrained to follow a third-degree polynomial pattern, the right-hand tail of the lag constrained to pass through zero, and the lead lag weight free of the polynomial constraint. ${ }^{24}$ The coefficients shown in Table 1 for the several distributed lag variables are in each case the sums of the estimated lag weights. The equity price distributed lags and the moving-average variances, by contrast, rely on uniform fixed weights.

The results shown in Table 1 are broadly consistent with the model of portfolio behavior developed in section II. The estimated equations explain a large percentage of the variation of the changes of holdings (net purchases) of long-term loans by all lender categories other than private pension funds. The demand for loans in each case responds positively to the currently prevailing nominal yield on long-term fixed-interest loans; negatively to currently prevailing nominal yields on competing assets; negatively to the expected yield on a series of one-period loans, as represented by the distributed lag on past one-period loan yields; and negatively to expected price inflation, as represented by the distributed lag on past price movements. Some lenders' loan demands also respond negatively to the expected capital gain on equities, as represented by the distributed lag on past equity price movements. The different moving-average variances appear in these equations in an irregular way; but the own-variance (calculated from realized net returns to holding corporate bonds) and the price variance enter negatively in each case, while the variances of competing asset yields enter positively in each case. 25

Table 2 summarizes, for all six categories of lenders, three key coefficients of the loan demand equation which are particularly relevant for assessing 
Table 2

SELECTED PARAMETER ESTIMATES FOR LOAN DEMAND

EQUATIONS BASED ON AUTOREGRESSIVE EXPECTATIONS

\begin{tabular}{|c|c|c|c|c|}
\hline Lender Category & $\hat{\beta}_{L L}$ & $\hat{\beta}_{\text {LP }}$ & $\hat{\theta}_{\text {LL }}$ & RMSE \\
\hline Life Insurance Companies & $\begin{array}{l}.219 \\
(2.9)\end{array}$ & $\begin{array}{l}-.322 \\
(-2.8)\end{array}$ & $\begin{array}{l}.355 \\
(5.6)\end{array}$ & 125 \\
\hline Other Insurance Companies & $\begin{array}{l}.050 \\
(6.2)\end{array}$ & - & $\begin{array}{l}.253 \\
(2.4)\end{array}$ & 33 \\
\hline Private Pension Funds & $\begin{array}{l}.100 \\
(3.1)\end{array}$ & $\begin{array}{l}-.098 \\
(-1.8)\end{array}$ & $\begin{array}{l}.463 \\
(2.5)\end{array}$ & 164 \\
\hline State-Local Retirement Funds & $\begin{array}{l}.077 \\
(2.0)\end{array}$ & $\begin{array}{l}-.123 \\
(-2.4)\end{array}$ & $\begin{array}{l}.267 \\
(2.8)\end{array}$ & 77 \\
\hline Mutual Savings Banks & $\begin{array}{l}.377 \\
(6.0)\end{array}$ & $\begin{array}{l}-.079 \\
(-1.5)\end{array}$ & $\begin{array}{l}.272 \\
(7.0)\end{array}$ & 84 \\
\hline Households & $\begin{array}{l}.070 \\
(5.1)\end{array}$ & $\begin{array}{c}-.033 \\
(-2.3)\end{array}$ & $\begin{array}{l}.284 \\
(4.0)\end{array}$ & 323 \\
\hline
\end{tabular}

Notes: Numbers in parentheses are ratios of estimated values to standard errors. RMSE in millions of dollars. 
the role of lenders' portfolio behavior in the relationship between expected price inflation and nominal interest rates.

First, the estimated own-yield coefficients $\hat{\beta}_{L L}$, from the specific loan equation (2) of the desired portfolio selection model (1), indicate the responsiveness of the desired fraction of loans in the portfolio. With the exception of mutual savings banks (for which $\hat{\beta}_{L L}$ is implausibly large), these estimates are all of credible magnitude in addition to being significantly greater than zero at high confidence levels. In each case the value of $\hat{B}_{L L}$ indicates the fractional increase in the share of the portfolio which the lender will want to allocate to long-term fixed-interest loans if, with all other things equal, the nominal own-yield on loans rises by one percentage point (that is, by 100 basis points).

Secondly, the estimated price expectations coefficients $\hat{\beta}_{L P^{\prime}}$ again from (2), indicate the responsiveness to expected inflation of the desired fraction of loans in the portfolio. These estimates are significantly different from zero, with the expected negative sign, for five of the six categories of lenders. 26 Hence the greater the expected inflation as inferred from recent observed inflation -- all other things, including the nominal loan interest rate, equal -- the smaller are these lenders' demands for fixed-interest loans. Following the discussion in Section II, this response may represent an explicit utility maximization of real rather than nominal wealth (or rate of return), or it may indicate that investors draw inferences about future interest rate movements (about future capital gains) from observations of price inflation. The magnitudes of the $\hat{B}_{L P}$ estimates provide support for the hypothesis that lenders seek to maximize the utility of some real quantity since, for four of the six lender groups, it is impossible to reject at the 108 confidence 
level the hypothesis $\hat{\beta}_{L P}=-\hat{\beta}_{I L}$. Nevertheless, since the estimated lag weight sums reported here are not identifiable as $\hat{\beta}_{\text {IP }}$ estimates without an arbitrary (though plausible) assumption that the true lag weights in the autoregressive expectation sum to unity, 27 it is not in general appropriate to assign these estimates a specific economic interpretation strictly comparable to the corresponding $\hat{\beta}_{L L}$. These estimates reflect the effect of observed price inflation on the demand for loans, including not only the effect of expected inflation on portfolio behavior but also the effect of observed inflation on expected inflation. 28

Thirdly, the $\hat{\theta}_{L L}$ estimates reflect the stock-adjustment component of the optimal marginal adjustment model (3). These estimates are significantly different from zero, with the expected positive sign, for all six categories of lenders. Their magnitudes roughly correspond to intuitive judgments of various lenders' respective likely speeds of portfolio adjustment based on institutional considerations; private pension funds, for example, which are typically managed very actively, undertake the most rapid re-allocation of their existing assets. ${ }^{29}$ Although these estimated adjustment speeds are fairly rapid in comparison to those typically found by previous researchers, they still indicate the existence of lags in portfolio behavior which will, in the short run, prevent nominal yields from immediately achieving their full adjustment to any stimulus affecting lenders' behavior -- including expected price inflation.

In addition, for purposes of comparison with the alternative set of loan demand equations estimated using the rational representation of the relevant unobservable expectations, Table 2 shows the root-mean-square forecast error for each of the six equations. 30 
Results Based on Rational Expectations. Recent researchers have broadly applied Muth's [52] concept of rational expectations, especially in the context of models dealing with the effectiveness of monetary policy. ${ }^{31}$ Expectations are rational, according to Muth's definition, if

$$
\tilde{x}_{t+1}=E_{t}\left(\tilde{x}_{t+1}\right)+\tilde{u}_{t+1}
$$

where $E_{t}(\cdot)$ is again the expectation conditional on all information available as of time $t$, and $u$ is a zero-mean finite-variance random disturbance which is serially uncorrelated as well as uncorrelated with $E_{t}(\cdot)$. In other words, expectations are rational in Muth's sense if the lender's expectation equals the mathematical expectation of the corresponding variable, conditional on all information available as of time t. ${ }^{32}$ As Frenkel [21] and Mussa [51] among others have shown in the specific context of price inflation, if the nature of the process generating realizations of the $x$ series is such that all relevant information is contained in past values of $x$ itself, then the autoregressive expectation is also the rational expectation. Nevertheless, even in simple models the necessary conditions for rational and autoregressive expectations to be identical are typically severe, so that it is useful to treat these two representations of expectations as distinct alternatives for estimation purposes.

As McCallum [46] and others have emphasized, in the absence of perfect foresight Muth's definition of rationality renders the realization $\tilde{x}_{t+1}$ in (7) distributed around, rather than equal to, the expectation $E_{t}\left(\tilde{x}_{t+1}\right)$, thereby leading to a classical errors-in-variables problem for estimation if actual values are simply used in place of the relevant expectations. The procedure used here to estimate loan demand equation (5) under rational expectations therefore replaces the actual values corresponding to the three 
relevant expectations -- of price inflation, capital gains on bonds, and capital gains on equities -- with their respective Brundy-Jorgenson instrumented values. While any valid instrument will give a consistent estimate of the coefficient of such an expectation, this instrument will give a more efficient estimate than the commonly suggested simpler one based only on past realizations of the series themselves if lenders, in forming their expectations, take account of the additional information on which the instrument is based. ${ }^{33}$ In the absence of any clear interpretation of the rationality definition for higher moments of distributions, the variance representations included in these equations are the same moving-average variances used in the equations presented above based on autoregressive expectations.

Table 3 shows the estimates and standard error ratios for two coefficients of the loan demand equations based on rational expectations. The estimated coefficients $\hat{\beta}_{L P}$ again indicate the responsiveness, to the (rational) expectation of price inflation, of the desired fraction of loans in the portfolio. The estimated coefficients $\hat{\beta}_{L C}$ analogously indicate the responsiveness of desired portfolio allocation to the (rational) expectation of capital gains on bonds. In sharp contrast to the corresponding estimates shown in Tables 1 and 2 for the loan demand equations based on autoregressive expectations, these coefficient estimates are significantly different from zero, with the expected signs (negative for $\hat{\beta}_{L P}$, positive for $\hat{\beta}_{L C}$ ) for only two and zero categories of lenders, respectively.

Table 3 also shows the root-mean-square forecast errors for each of the six loan demand equations estimated using the rational expectations procedure. In each of the six cases, this error is greater than the error shown in Table 2 for the corresponding loan demand equation based on autoregressive expectations. These root-mean-square errors are essential to a valid comparison 
Table 3

SELECTED PARAMETER ESTIMATES FOR LOAN DEMAND

EQUATIONS BASED ON RATIONAL EXPECTATIONS

Lender Category

Life Insurance Companies

Other Insurance Companies

Private Pension Funds

State-Local Retirement Funds

Mutual Savings Banks

Households $\hat{\beta}_{\text {IP }}$

$$
-.0471
$$$$
(-1.1)
$$

.0517

(1.0)

.0215

(1.2)

.00740

$(0.4)$

$-.0369$

$(-3.6)$

$-.0292$

$(-4.3)$
$\hat{\beta}_{L C}$

RMSE

221

$(0.3)$

$-.00278$

$(-1.2)$

129

.0000375

190

$(0.0)$

$-.00247$

$(-2.0)$

98

100

$(-3.3)$

$-.0000555$

$(-0.1)$

Notes: Numbers in parentheses are ratios of estimated values to standard errors. RMSE in millions of dollars. 
of the two sets of results, since high multicollinearity between the price inflation and capital gain series (as would be expected under perfect arbitrage) could in principle explain the weakness of the $\hat{\beta}_{L P}$ and $\hat{\beta}_{L C}$ estimates. By contrast, the respective root-mean-square errors are not sensitive to multicollinearity, and their comparison -- which uniformly favors the equations based on the autoregressive expectations proxies -- is analogous to an F-test rather than the $t$-tests reported for the individual parameter estimates. Section IV presents a partial-equilibrium analysis of the role of lenders' portfolio behavior in the relationship between expected price inflation and nominal interest rates, based on the autoregressive expectations version of the loan demand equations shown in full in Table 1. 
IV. Expected Price Inflation and Nominal Interest Rates

The equations developed and estimated in section III represent lenders' demand for loans. These six equations, together with some representation of borrowers' supply of loans, therefore constitute a complete model of the loan market. Adding the market-clearing equilibrium condition

$$
\sum_{j=1}^{6} L_{t}^{j}=\bar{L}_{t},
$$

where $\overline{\mathrm{L}}$ is the supply of loans, thereby enables the model to determine the nominal loan yield which is an argument of each of the six estimated loan demand equations. 34 Furthermore, since five of these six equations explicitly include expected price inflation as another independent variable, the nominal loan yield determined in this model is an implicit function of expected inflation.

Figure 1 illustrates in $\left(r_{L}, L\right)$ space how a partial-equilibrium analysis based on the six estimated loan demand equations and equilibrium condition (8), with loan supply taken as given, isolates the contribution of lenders' portfolio behavior to the expected-price-inflation/nominal-interest-rate relationship. The object of this analysis is to show how the nominal loan yield would respond to expected inflation if all aspects of economic behavior other than lenders' portfolio behavior remained unchanged. In particular, the assumption of given investable cash flows (which are important arguments of the loan demand equations) holds unchanged all decisions about how much to save, and the assumption of a given loan supply analogously holds unchanged not only all decisions about how much to invest but also borrowers' decisions with respect to the composition of their liabilities.

In Figure 1 the upward sloping curve $L\left(\bar{p}^{-e}\right)$, which represents the aggregated 


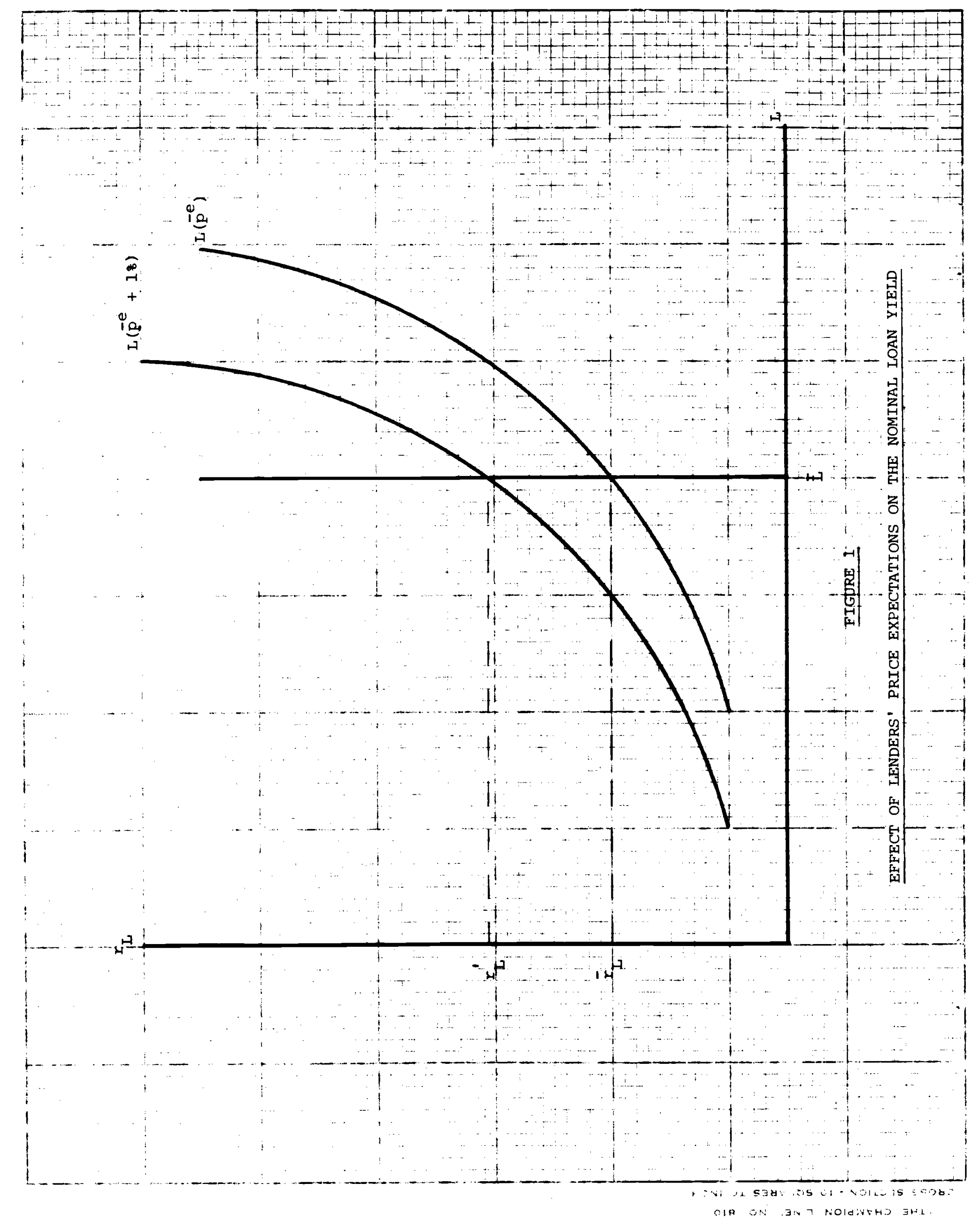


demand for loans conditional on some fixed expectation of price inflation $\bar{p}^{e}$, intersects the fixed loan supply $\bar{L}$ at interest rate $\bar{r}_{L}$. Curve $L\left(\bar{p}^{e}+1 z\right)$, which represents the demand for loans conditional on an inflation expectation 18 greater, is shifted to the left from $L\left(\bar{p}^{-}\right)$, indicating lenders' reduced willingness to hold bonds at any given nominal interest rate. Curve $L(\bar{p}+18)$ therefore intersects $\overline{\mathrm{L}}$ at interest rate $r_{L}^{\prime}>\bar{r}_{I^{\prime}}$ and the difference $\left(r_{L}^{\prime}-\bar{r}_{L}\right)-$ that is, the "upward shift" measured by the vertical distance between $L\left(\bar{p}^{e}+1 q\right)$ and $L\left(\bar{p}^{e}\right)$ for a given $\bar{L}$-- indicates the increase in $r_{L}$ which makes lenders content to hold exactly $\bar{L}$ loans after an increase of 18 in their expectation of price inflation.

Figure 2 and Table 4 summarize the results of a dynamic version of such a partial-equilibrium analysis based on the six estimated loan demand functions from Section III, the market equilibrium condition (8), and given loan supply. The heavy solid line in Figure 2 plots the observed historical values of the nominal loan yield which, as Table 4 shows, averaged $6.07 \%$ over the 1960-73 sample period. The light solid line in the figure plots the simulated values of the nominal loan yield from the model of lenders' portfolio behavior. This "control" simulation, based on historical values of all exogenous variables (including distributed lags on observed price inflation in place of the unobservable inflation expectation), is fully dynamic in that, after the first quarter of the simulation, the solution uses internally generated values for the lagged own-stock variables $L_{t-1}$ in each of the six loan demand equations.

This control simulation indicates that the partial-equilibrium loan market model reproduces the relevant historical experience with reasonable accuracy. There is no significant bias for any of the model's seven jointly determined variables, and, as Table 4 shows, the mean simulated value of the nominal loan 


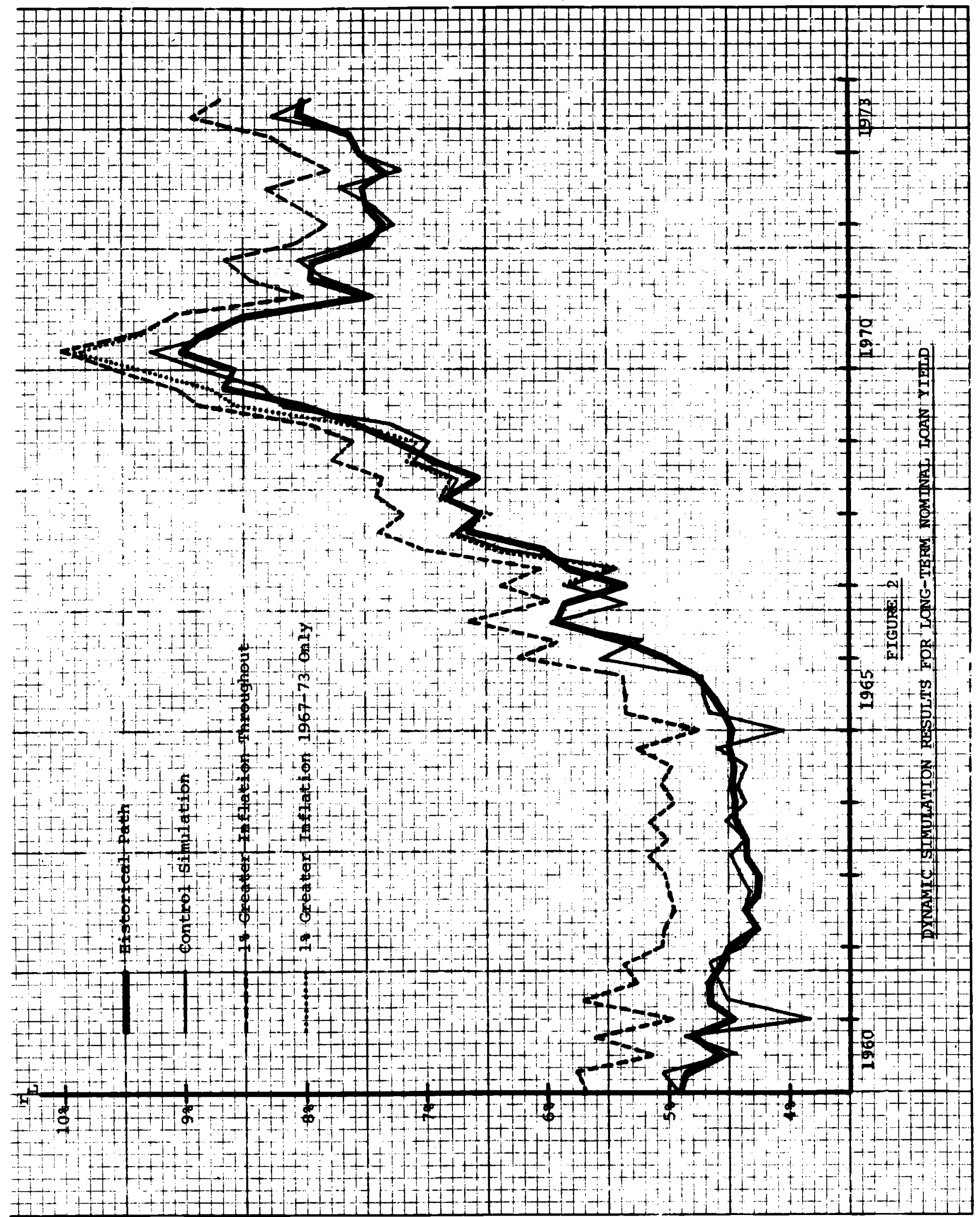


Table 4

NOMINAL LOAN YIELD DYNAMIC SIMULATIONS

1960-73

Average Yield

Historical

Control Simulation

1 - Greater Inflation Experiment
6.078

6.07

6.72
$0.00 \%$

0.65

Difference from Historical

-
$0.00 \%$
0.65


yield is precisely 6.078. For the six loan demand variables, the root-meansquare dynamic simulation errors are about in line with those shown in Table 2, indicating that the errors made by individual equations have no observable tendency to compound one another. ${ }^{35}$ For the nominal loan yield, the root-meansquare dynamic simulation error is 0.218 (that is, 21 basis points) -- about comparable to the "fit" achieved by previous researchers who have directly estimated reduced-form equations for long-term nominal interest rates. ${ }^{36}$ This within-sample performance seems quite creditable, especially since the methodology of the structural model does not estimate an equation directly for this yield but, instead, implies an equation for the yield which is restricted by the underlying structural hypotheses about lenders' portfolio behavior. 37

What equilibrium adjustment in the nominal interest rate, equivalent to the difference between $r_{L}^{\prime}$ and $\bar{r}_{L}$ in Figure 1 , will lenders' portfolio behavior induce in response to greater expectations of price inflation? The broken line in Figure 2 plots the simulated values of the nominal loan yield from an alternative simulation which differs from the control only in that the expected rate of price inflation is 18 greater throughout the simulation period. Specifically, this simulation experiment is based on values of the rate of change of consumer prices which, from as long before 1960 as is consistent with the distributed-lag price expectations terms in the estimated loan demand equations, are 18 greater than the corresponding historical values. In all other respects this simulation is identical to the control.

Since the demand for loans by five categories of lenders responds negatively to the greater expectations of price inflation, ${ }^{38}$ the nominal loan yield must rise as in Figure 1 if total loan demand is still to equal total loan supply. As the broken line in Figure 2 shows, the market-clearing level of the nominal 
yield in this experiment is strictly greater than the control simulation level throughout the simulation period. The mean simulated value of the nominal yield in this experiment $\left(r_{L}^{\prime}\right)$, as Table 4 shows, is 6.728 -- an increase of 0.658 above the control simulation mean $\left(\bar{r}_{L}\right){ }^{39}$

Finally, what is the dynamic speed by which lenders' portfolio behavior will bring about this 0.658 equilibrium adjustment? The dotted line in Figure 2 plots the simulated values of the nominal loan yield from a further experiment in which the 18 increase in the assumed rate of price inflation, in comparison with the control, is effective only in 1966:IV and thereafter. Hence this experiment's results for 1960-66 are identical to those of the control simulation. As of 1967:I, however, the simulated nominal loan yield begins to rise above the control path. By 1971:I -- that is, after four years -- the adjustment to the new equilibrium path, which is identical to that of the first simulation experiment, is essentially complete.

These simple partial-equilibrium experiments cannot, of course, represent the complete nature of the expected-price-inflation/nominal-interest-rate relationship. In the first instance, the intent motivating their construction is not to model all of the underlying economic behavior but rather to isolate the role of lenders' portfolio behavior. Borrowers' portfolio behavior, for example, presumably corresponds to a downward sloping loan supply curve instead of the vertical $\overline{\mathrm{L}}$ in Figure 1 , and the equilibrium adjustment of the interest rate will be greater (less) than 0.658 if the "upward shift" of the supply curve is greater (less) than the 0.658 found here for the aggregated demand curve. 40 This analysis also abstracts from the influences of saving and investment behavior as discussed in section $I$. In addition, as the discussion of Section II notes, even the lenders' portfolio behavior modeled here applies 
only to one market -- that for long-term fixed-interest loans -- rather than to the complete set of all asset and liability markets. Nevertheless, these partial-equilibrium experiments are instructive in showing that lenders' portfolio behavior is an important part of the Fisher relationship, that this behavior alone is likely to yield a large (but less than one-for-one) equilibrium adjustment of nominal interest rates to expected price inflation, and that the dynamic path toward the equilibrium adjustment involves a substantial time lag. 


\section{v. Summary of Conclusions}

Both the equilibrium extent and the dynamic path of the adjustment of nominal interest rates to expected price inflation are important questions for monetary theory and policy. The role of portfolio behavior is especially interesting in this context because, of the different kinds of economic behavior which may underlie the Fisher relationship, it is the most plausibly flexible in the short rum. Even so, since substitution into real assets is not a practical portfolio alternative for many investors, it is not obvious a priori how important lenders' portfolio behavior is in this relationship. The empirical results presented in this paper indicate that lenders' portfolio behavior does play an important role in the expected-price-inflation/ nominal-interest-rate relationship.

First, at the single-equation level, the results provide evidence that, with all other things equal, five of the six major categories of lenders in the U.S. long-term fixed-interest loan market reduce their demands for loans in response to an increase in expected inflation. Even life insurance companies, whose liabilities are almost entirely in nominal form, respond to price expectations in this way.

Secondly, at the multi-equation partial-equilibrium level, the results indicate that, with all other things equal, this response by lenders will raise the equilibrium nominal loan yield by 0.65 in response to a 18 increase in expected inflation. The results also indicate that this 0.658 adjustment requires approximately four years for completion. 
Footnotes

* The author is grateful to David Jones and Vance Roley for research assistance, and to James Duesenberry, Stanley Fischer, David Jones, Robert King, John Lintner, Thomas Mayer, Allan Meltzer, Franco Modigliani, Vance Roley, John Rutledge, Jerome Stein and James Tobin for helpful discussions and comments on a previous draft of this paper. The author also gratefully acknowledges the research support of the National science Foundation, under grant APR77-14160, and the National Bureau of Economic Research.

1. See especially Fisher [17], [18, Ch. 5] and [19, Ch. 19]; emphasis added.

2. Prominent examples include Cargill [8], Fama [12], Feldstein and Chamberlain [14], Feldstein and Eckstein [15], Gibson [31, 32], Lahiri [38], Modigliani and Shiller [48], Pesando [54], Pyle [55], Sargent [60,62], and Yohe and Karnosky [72].

3. See Fisher [19, pp. 438-442]. Somewhat astonishingly to the modern reader, Fisher's suggested "interpretation" followed wicksell [71] in noting that higher prices usually meant a greater nominal volume of trade, which in turn increased the demand for money, and hence increased nominal interest rates for given bank reserves. What is surprising about this "interpretation" is that, as rendered by Fisher, it has nothing whatever to do with expectations. In addition, the association of higher prices with a greater nominal transactions volume is necessarily valid only if the source of the inflation is a demand shock to the economy; under a supply shock prices rise but real transactions volume falls, so that the change in nominal transactions volume remains ambiguous in general.

4. See Friedman [26] for an analogous treatment of the role of borrowers' portfolio behavior.

5. On invariance of the real rate with respect to inflation [19, p. 493] : "... in actual practice... the appreciation or depreciation of the monetary standard does produce a real effect on the rate of interest... This effect, in times of great changes in the purchasing power of money, is by far the greatest of all effects on the rate of interest." On constancy of the real rate for given inflation [19, p. 411]: "...there are...so many other causes affecting the rate of interest besides changes in the price level." These views clearly contradict such interpretations as the "Fisherian" proposition tested in Fama [12].

6. See Fisher [17, pp. 75-78] and the useful discussion in Rutledge [56].

7. See again the references cited in footnote 2. Froyen and Davidson [30] argued (along the lines taken below) in favor of a structural modelling approach, but their empirical work also relied on a reduced-form model.

8. See Sargent [63] for a forceful statement of this point.

9. The concept of the nominal yield's being "proximately determined" in the loan market is not inconsistent with the principle of general equilibrium in the asset markets (see, for example, Tobin [70]) or for the economy as a whole (see, for example, Grossman [34]). In well developed financial 
markets, of course, the relevant group of "lenders" include not only those who make primary loans directly to borrowers but also those who may under certain circumstances be willing to acquire debt securities in a secondary market.

10. In simple consumption-loan models there is typically no meaningful distinction between saving behavior and portfolio behavior in the conventional sense as meant here; see, for example, Samuelson [58]. It is also worth noting that, even in models in which the two kinds of behavior have distinct meanings, they are not in general independent; see, for example, Fama [11], Merton [47], and Samuelson [59]. Hence the portfolio behavior analyzed in Section II below implicitly relies on a single-period horizon.

11. See, for example, Bodie [2], Cagan [7], and Lintner [40].

12. This argument is parallel to that of Fisher and Wicksell, but it differs in that it involves expectations in a fundamental way; see again footnote 3.

13. While capital loss avoiding behavior as in these two examples clearly indicates a connection between expected price inflation and long-term interest rates, this argument does not carry over to short-term interest rates. Hence it may be more accurate to refer to such effects as "termstructure effects" rather than "Fisher effects," but it is difficult to support any such sharp distinction on the basis of Fisher's own work; see again footnote 12 .

14. See Lintner $[39,41]$, for example, for the precise derivation of asset demand functions from maximization of a negative exponential (or logarithmic) utility function under the normality (or lognormality) assumption. Alternatively, as Tobin [68] and Markowitz [45] have shown, the first and second moments of the yield distributions are sufficient to determine asset demands, regardless of the distribution assumed, if utility is quadratic.

15. See Friedman [25] for a review of the alternative sets of assumptions which permit the derivation of asset demand functions that satisfy the homogeneity property and that are linear in expected asset yields; de Leeuw [10] and M. Friedman [29] also provided discussions of the rationale behind the homogeneity constraint. Asset demand functions of this form are familiar in both empirical (e.g., de Leeuw) and abstract (e.g., Brainard and Tobin [4]) work on portfolio behavior in monetary economics. A particular advantage of the homogenous form, in the context of this paper's concern with price inflation, is that rising dollar magnitudes per se do not affect the portfolio allocation.

16. See Stiglitz [67] for a demonstration that these two propositions are equivalent. Modigliani and Shiller [48] provided a useful discussion of the role of price expectations in differentially influencing the expected holding yields on short- versus long-term bonds.

17. See Foley [20] for a useful analysis of this issue. 
18. See Friedman [23]. It is worth noting explicitly that the nonlinear way in which the flow $\Delta W_{t}$ matters for short-run portfolio behavior in the optimal marginal adjustment model is in sharp contrast to the work of Bosworth and Duesenberry [3] and Hendershott and Lemmon [35] who, without explicitly developing an underlying model of portfolio adjustment, emphasized linear dependence on the cash flow.

19. The household sector as defined here primarily consists of individuals but also includes non-profit organizations and bank-managed personal trusts.

20. See Friedman [23] for further details on precise definitions of variables, in particular the cash flows of life insurance companies and households and dummy variables in the two insurance company equations.

21. See, for example, Sargent [64], Rutledge [56] and McCallum. [46].

22. Because of the nonlinear way in which both expected yields and variances enter the model, as indicated in (5), all such terms are products. The correct instrument to use in each such case, for purposes of deriving consistent estimators, is the first-stage fitted value of the entire product; this procedure is used here.

23. Because of the instrumental variables estimation procedure, the standard error ratios shown are asymptotically distributed as $t$-statistics but are not necessarily distributed as t-statistics in small samples.

24. The estimation of these distributed lags presents an interesting identification problem due to the potential appearance of each distributed lag in two separate nonlinear terms on the right-hand side of each single loan demand equation. See Friedman and Roley [27] for the derivation of the method used to solve the resulting estimation problem.

25. See Friedman [23] and Friedman and Roley [28] for further details of the exact procedures used in deriving the equations' final specifications. It is interesting that the standard error ratios of the variance terms are uniformly smaller (in absolute value) in these equations than in the corresponding ordinary-least-squares estimates.

26. This coefficient was insignificant in the loan demand equation for nonlife insurance companies, and so the $\left(\Sigma \zeta_{i} \dot{p}_{t-i}\right) \cdot \Delta w_{t}$ term is omitted from the final specification. That equation includes the price expectations distributed $\mathrm{lag}$ in the term $\left(\sum \zeta_{i} \dot{P}_{t-i}\right) \cdot w_{t-1}$, but, as the discussion of

(5) in Section II indicates, the coefficient of this term is a sum of products of parameters in the underlying model consisting of (1) and (3). The standard error ratio for the coefficient of the $\left(\sum \zeta_{i} \dot{P}_{t-i}\right) \cdot \Delta w_{t}$ term

in the equation for mutual savings banks is small, but the F-test indicates that this lag structure is significant at the 58 confidence level. 
27. The unit sum constraint implies that lenders believe that the stochastic process generating the price inflation is borderline stationary/nonstationary -- that is, any rate of inflation which has persisted for a long time will continue to persist. U.S. survey evidence suggests that inflation expectations in the 1970s do differ from those of the 1950s and 1960s in such a way as to render this borderline stationary/nonstationary specification plausible. Alternatively, for the process to be stationary, the lag weights in the estimated equations would have to sum to less than unity, and the expectation would also have to include a constant term. Several other writers have also emphasized this point; see, for example, Lucas [42] and Sargent [61].

28. Another reason for caution in interpreting the $\hat{\beta}_{I P}$ estimates is the potential difficulty of distinguishing first- from second-mament effects. Gordon and Halpern [33], for example, have argued that the mean of the inflation rate is a good proxy for the associated uncertainty; such an effect here would bias upward the absolute values of the $\hat{\beta}_{\text {IP }}$ estimates. In addition, the estimated equations for the two categories of taxable investors do not allow for specific tax effects, which have shifted during the sample period; see, for example, Feldstein and summers [16].

29. This interpretation of the $\theta_{i i}$ estimates is merely heuristic, however, since in a multivariate stock-adjustment model the "speed of adjustment" depends on the eigenvalues of the entire matrix of $\theta_{i j}$ coefficients, not just the on-diagonal $\theta_{i i}$ values.

30. For equations estimated by an instrumental variables procedure, the rootmean-square forecast error (computed from the actual values of all righthand-side variables) is a better measure of statistical performance than is the estimated standard error (computed from instrumented values of the right-hand-side variables).

31. See, for example, Lucas [43] and Sargent and Wallace [65].

32. It is worth pointing out that the information available as of time $t$ must include, to within a set of additive white noise disturbances, knowledge of the model which will generate the actual outcome $x_{t+1}$; hence this definition of rationality is stronger than the usual notion of using efficiently all available information. For further discussion of the informational implications of assuming rationality in this sense, see Friedman [24].

33. Fully efficient estimates, of course, would require instruments based on the model which lenders actually used to form their expectations.

34. Since the six categories of lenders whose portfolio behavior is explicitly represented in the estimated loan demand equations do not hold all of the outstanding loans, $\bar{L}$ is more precisely the supply of loans minus those loans held by other lenders. 
35. The RMSE values for the six lender categories, in their order of appearance in Table 2 , are 120, 36, 176, 87, 114 and 247, respectively.

36. Modigliani and Shiller's [48] preferred equation had $\mathrm{SE}=0.138$ for the less volatile Aaa yield over the sample period 1955:III-1971:II. Reestimating the Modigliani-Shiller equation using the Aa yield and the 1960:I-1973: IV sample period leads to an equation with $\mathrm{SE}=0.228$ but with the coefficients of the distributed lag on the short-term yield not significantly different from zero. Feldstein and Eckstein's [15] preferred equation had $\mathrm{SE}=0.098$ for the Aaa yield over the sample period 1954:I-1969:II. Re-estimating the Feldstein-Eckstein equation using the $\mathrm{Aa}$ yield and the 1960:I-1973:IV sample period leads to an equation with $S E=0.298$. Feldstein and Chamberlain's [14] preferred equation had $S E=0.21 \%$ for the Aaa yield over the sample period $1954: I-1971: I$.

37. This point is especially relevant to the presence of other long-term yields in the estimated loan demand equations for several categories of lenders. Including other long-term yields as independent variables in an unrestricted equation with the bond yield as dependent variable would presumably increase greatly such an equation's fit. In the context of the structural model, however, the contribution of other long-term yields is restricted to their role in influencing the net purchases variables. See Friedman [23] for a discussion of the structural modeling methodology as specifically applied to the determination of long-term interest rates.

38. Since the $\left(\sum_{i} \zeta_{i} \dot{P}_{t-i}\right) \cdot w_{t-1}$ terms which appear in the loan demand equations for three categories of lenders reflect these lenders' behavior in other markets, the solution used the historical $\dot{P}$ values for these variables and introduced the 18 increase only in the $\left(\sum_{i} \zeta_{i} \dot{P}_{t-i}\right) \cdot \Delta w_{t}$ terms. See

39. An alternative to taking means over simulated values is simply to solve the model using the sample-period means of the exogenous variables. This reverse strategy yields an estimate of 0.708 instead of $0.65 \%$. The difference is due to the model's nonlinearity.

40. The analogous experiments in Friedman [26] indicate that the loan supply curve actually "shifts upward" by slightly less than $0.65 \%$ for an additional 18 of expected price inflation, so that the net upward adjustment of the interest rate is slightly less than that indicated by the analysis of lenders' behavior alone, and the resulting quantity $\mathrm{L}$ is slightly below $\overline{\mathrm{L}}$. 


\section{References}

1. Board of Governors of the Federal Reserve System. Flow of Funds Accounts 1945-72. Washington, 1973.

2. Bodie, Zvi. "Common Stocks as a Hedge Against Inflation." Journal of Finance, XXI (May, 1976), 459-470.

3. Bosworth, Barry, and Duesenberry, James S. "A Flow of Funds Model and Its Implications." Federal Reserve Bank of Boston, Issues in Federal Debt Management. Boston: Federal Reserve Bank of Boston, 1973.

4. Brainard, William C., and Tobin, James. "Pitfalls in Financial ModelBuilding:" American Economic Review, LVII (May, 1968), 99-122.

5. Brundy, James M., and Jorgenson, Dale W. "Efficient Estimation of Simultaneous Equations by Instrumental Variables." Review of Economics and Statistics, LIII (August, 1971), 207-224.

6. Cagan, Phillip. "The Monetary Dynamics of Hyperinflation." Friedman (ed.), Studies in the Quantity Theory of Money. Chicago: University of Chicago Press, 1956.

7. Cagan, Phillip. "Common Stock Values and Inflation -- The Historical Record of Many Countries." New York: National Bureau of Economic Research, 1974.

8. Cargill, Thomas. "Anticipated Price Changes and Nominal Interest Rates in the 1950's." Review of Economics and Statistics, LVIII (August, 1976), 364-367.

9. Darby, Michael R. "The Financial and Tax Effects of Monetary Policy on Interest Rates." Economic Inquiry, XIII (June, 1975), 266-276.

10. De Leeuw, Frank. "A Model of Financial Behavior." Duesenberry et al. (eds.). The Brookings Quarterly Econometric Model of the United States. Chicago: Rand McNally \& Company, 1965.

11. Fama, Eugene F. "Multiperiod Consumption-Investment Decisions." American Economic Review, Lx (March, 1970), 163-174.

12. Fama, Eugene F. "Short-term Interest Rates as Predictors of Inflation." American Economic Review, IXV (June, 1975), 269-282.

13. Feldstein, Martin. "Inflation, Income Taxes and the Rate of Interest: A Theoretical Analysis." American Economic Review, LXVI (December, 1976), 809-820.

14. Feldstein, Martin, and Chamberlain, Gary. "Multimarket Expectations and the Rate of Interest." Journal of Money, Credit and Banking, V

(November, 1973), 373-902. 
15. Feldstein, Martin, and Eckstein, Otto. "The Fundamental Determinants of the Interest Rate." Review of Economics and Statistics, III (November, 1970), 363-375.

16. Feldstein, Martin, and Summers, Lawrence. "Inflation, Tax Rules, and the Long-Term Interest Rate." Brookings Papers on Economic Activity, forthcoming.

17. Fisher, Irving. Appreciation and Interest. New York: The Macmillan Company, 1896.

18. Fisher, Irving. The Rate of Interest. New York: The Macmillan Company, 1907.

19. Fisher, Irving. The Theory of Interest. New York: The Macmillan Company, 1930.

20. Foley, Duncan K. "On Two Specifications of Asset Equilibrium in Macroeconomic Models." Journal of Political Economy, LXXXIII (April, 1975), 303-324.

21. Frenkel, Jacob A. "Inflation and the Formation of Expectations." Journal of Monetary Economics, I (October, 1975), 403-421.

22. Friedman, Benjamin M. "Substitution and Expectation Effects on Long-Term Borrowing Behavior and Long-Term Interest Rates." Mimeo, Harvard University, 1976.

23. Friedman, Benjamin M. "Financial Flow Variables and the Short-Run Determination of Long-Term Interest Rates." Journal of Political Economy, IXXXV (August, 1977), 661-689.

24. Friedman, Benjamin M. "Optimal Expectations and the Extreme Information Assumptions of 'Rational Expectations' Macromodels." Mimeo, Harvard University, 1977.

25. Friedman, Benjamin M. "The Effect of Wealth shifts on the Term Structure of Interest Rates." Mimeo, Harvard University, 1977.

26. Friedman, Benjamin M. "Who Puts the Inflation Premium into Nominal Interest Rates?" Journal of Finance, forthcoming.

27. Friedman, Benjamin M., and Roley, V. Vance. "Identifying Identical Distributed Lag Structures by the Use of Prior Sum Constraints." Annals of Economic and Social Measurement, VI (Fall, 1977), 429-444.

28. Friedman, Benjamin M., and Roley, v. Vance. "Investors' Portfolio Behavior Under Alternative Models of Iong-Term Interest Rate Expectations: Unitary, Rational or Autoregressive." Mimeo, Harvard University, 1977.

29. Friedman, Milton. "The Quantity Theory of Money: A Restatement." Friedman (ed.), Studies in the Quantity Theory of Money, Chicago: University of Chicago Press, 1956. 
30. Froyen, Richard T., and Davidson, Lawrence S. "Estimates of the 'Fisher Effect': A Structural Model Approach." Mimeo, University of 31. Gibson, William. "Price Expectations and Interest Rates." Journal of
Finance, XXV (March, 1970), 19-34.

32. Gibson, William. "Interest Rates and Inflationary Expectations." American Economic Review, LXII (December, 1972), 854-865.

33. Gordon, Myron J., and Halpern, Paul J. "Bond Share Yield Spreads Under Uncertain Inflation." American Economic Review, LXVI (September, 1976),
559-565.

34. Grossman, Herschel. "Money, Interest and Prices in Market Disequilibrium." Journal of Political Economy, LXXIX (September/October, 1971), 943-961.

35. Hendershott, Patric H., and Lemmon, Richard C. "A Flow of Funds Model: First Estimates and Forecasts." American Statistical Association, Proceedings (1973 Business and Economics Section), 112-121.

36. Hicks, John R. Value and Capital. London: Oxford University Press, 1939.

37. Ladenson, Mark L. "Pitfalls in Financial Model Building: Some Extensions." American Economic Review, LXI (March, 1971), 179-186.

38. Lahiri, Kajal. "Inflationary Expectations: Their Formation and Interest
Rate Effects." Rate Effects." American Economic Review, LXVI (March, 1976), 124-131.

39. Lintner, John. "The Valuation of Risky Assets and the Selection of Risky Investments in Stock Portfolios and Capital Budgets." Review of Economics
and Statistics, XLVII (February, 1965), 13-37.

40. Lintner, John. "Inflation and Securities Returns." Journal of Finance,
Xxx (May, 1975), 259-280. 41. Lintner, John. "The Lognormality of Security Returns, Portfolio Selection
and Market Equilibrium." Mimeo, Harvard University, 1975.

42. Lucas, Robert E. "Econometric Testing of the Natural Rate Hypothesis." Eckstein (ed.), The Econometrics of Price Determination. Washington: 43. Lucas, Robert E. "An Equilibrium Model of the Business Cycle." Journal
of Political Economy, LXXXIII (December, 1975), 1113-1144. 44. Lutz, Friedrich A. "The Structure of Interest Rates." Quarterly Journal
of Economics, LIV (November, 1940), 36-63.

45. Markowitz, Harry. "Portfolio Selection." Journal of Finance, VII
(March, 1952), 77-91.

46. McCallum, B.T. "Rational Expectations and the Natural Rate Hypothesis: Some Consistent Estimates." Econometrica, XLIV (January, 1976), 43-52. 
47. Merton, Robert C. "Lifetime Portfolio Selection Under Uncertainty: The Continuous-time Case." Review of Economics and Statistics, LI (August, 1969), 247-257.

48. Modigliani, Franco, and Shiller, Robert J. "Inflation, Rational Expectations, and the Term Structure of Interest Rates." Economica, XL (February, 1973), 12-43.

49. Modigliani, Franco, and Sutch, Richard. "Innovations in Interest Rate Policy." American Economic Review, LVI (May, 1966), 178-197.

50. Mundell, Robert. "Inflation and Real Interest." Journal of Political Economy, LXXI (June, 1963), 280-283.

51. Mussa, Michael. "Adaptive and Regressive Expectations in a Rational Model of the Inflationary Process." Journal of Monetary Economics, I (October, 1975), 423-442.

52. Muth, John F. "Rational Expectations and the Theory of Price Movements." Econometrica, XXIX (July, 1961), 315-335.

53. Nerlove, Marc. "Distributed Lags and Unobserved Components in Economic Time Series." Fellner et al., Ten Economic Studies in the Tradition of Irving Fisher. New York: John Wiley \& Sons, Inc., 1967.

54. Pesando, James E. "Determinants of Term Premiums in the Market for United States Treasury Bills." Journal of Finance, XXX (December, 1975), 1317-1327.

55. Pyle, David. "Observed Price Expectations and Interest Rates." Review of Economics and Statistics, LIV (August, 1972), 275-280.

56. Rutledge, John. A Monetarist Model of Inflationary Expectations. Lexington: D. C. Heath and Company, 1974.

57. Rutledge, John. "Irving Fisher and Autoregressive Expectations." American Economic Review, LXVII (February, 1977), 200-205.

58. Samuelson, Paul A. "An Exact Consumption-Loan Model of Interest with or without the Social Contrivance of Money." Journal of Political Economy, LXVI (December, 1958), 467-482.

59. Samuelson, Paul A. "Lifetime Portfolio Selection by Dynamic Stochastic Programing." Review of Economics and Statistics, LI (August, 1969), 239-246.

60. Sargent, Thomas J. "Commodity Price Expectations and the Interest Rate." Quarterly Journal of Economics, LXXXIII (February, 1969), 127-140.

61. Sargent, Thomas J. "A Note on the 'Accelerationist' Controversy." Journal of Money, Credit and Banking, III (August, 1971), 721-725.

62. Sargent, Thomas J. "Anticipated Inflation and Nominal Interest." quarterly Journal of Economics, LXXXVI (May, 1972), 212-225. 
63. Sargent, Thomas J. "The Fundamental Determinants of the Interest Rate: A Comment." Review of Economics and Statistics, IV (August, 1973), 391-393.

64. Sargent, Thomas J. "Rational Expecţations, the Real Rate of Interest, and the Natural Rate of Unemployment." Brookings Papers on Economic Activity (No. 2, 1973), 429-472.

65. Sargent, Thomas J., and Wallace, Neil. "'Rational' Expectations, the Optimal Monetary Instrument, and the Optimal Money Supply Rule." Journal of Political Economy, LXXXIII (April, 1975), 241-254.

66. Smith, Gary. "Pitfalls in Financial Model Building: A Clarification." American Economic Review, LxV (June, 1975), 510-516.

67. Stiglitz, J.E. "A Consumption-oriented Theory of the Demand for Financial Assets and the Term Structure of Interest Rates." The Review of Economic Studies, XXXVII (July, 1970), 321-351.

68. Tobin, James. "Liquidity Preference as Behavior Towards Risk." Review of Economic Studies, XXV (February, 1958), 65-86.

69. Tobin, James. "Money and Economic Growth." Econometrica, XXXIII (October, 1965), 671-684.

70. Tobin, James. "A General Equilibrium Approach to Monetary Theory." Journal of Money, Credit and Banking, I (February, 1969), 15-29.

71. Wicksell, Knut. "The Influence of the Interest Rate on Prices." Economic Journal, XVII (June, 1907), 213-220.

72. Yohe, William P., and Karnosky, Denis S. "Interest Rates and Price Level Changes." Federal Reserve Bank of St. Louis, Review, II (December, 1969), 19-36. 